\title{
SIMILARITY SOLUTIONS OF MIXED CONVECTION BOUNDARY-LAYER FLOWS IN A POROUS MEDIUM
}

\author{
MOHAMmed AÏBOUdi, IKRAM BENSARI-KHELIL AND BERNARD BRIGHI
}

Abstract. The similarity differential equation $f^{\prime \prime \prime}+f f^{\prime \prime}+\beta f^{\prime}\left(f^{\prime}-1\right)=0$ with $\beta>0$ is considered. This differential equation appears in the study of mixed convection boundary-layer flows over a vertical surface embedded in a porous medium. In order to prove the existence of solutions satisfying the boundary conditions $f(0)=a \geqslant 0, f^{\prime}(0)=b \geqslant 0$ and $f^{\prime}(+\infty)=0$ or 1 , we use shooting and consider the initial value problem consisting of the differential equation and the initial conditions $f(0)=a, f^{\prime}(0)=b$ and $f^{\prime \prime}(0)=c$. For $0<\beta \leqslant 1$, we prove that there exists a unique solution such that $f^{\prime}(+\infty)=0$, and infinitely many solutions such that $f^{\prime}(+\infty)=1$. For $\beta>1$, we give only partial results and show some differences with the previous case.

Mathematics subject classification (2010): 34B15, 34C11, 76D10.

Keywords and phrases: Fluid mechanics, boundary layer, mixed convection, similarity solution, third order nonlinear differential equation, boundary value problem.

\section{REFERENCES}

[1] R. C. Ackerberg, Boundary layer separation at a free stream-line, J. Fluid Mech., 44 (1970) 211 226.

[2] M. AÏBOUDI AND B. BRIGHI, On the solutions of a boundary value problem arising in free convection with prescribed heat flux, Arch. Math., 93, 2 (2009) 165-174.

[3] E. H. Aly, L. ElliotT AND D. B. Ingham, Mixed convection boundary-layer flows over a vertical surface embedded in a porous medium, European J. Mech. B/Fluids, 22 (2003) 529-543.

[4] Z. BELHACHMI, B. BRIGHI AND K. TAOUS, On a family of differential equations for boundary layer approximations in porous media, European J. Appl. Math., 12, 4 (2001) 513-528.

[5] I. BenSARI-KHELIL, Ph'D Thesis, in preparation.

[6] H. Blasius, Grenzschichten in Flüssigkeiten mit kleiner Reibung, Z. Math. Phys., 56 (1908) 1-37.

[7] B. BRIGHI, On a similarity boundary layer equation, Z. Anal. Anwendungen, 21, 4 (2002) 931-948.

[8] B. BRIGHI, Sur un problème aux limites associé à l'équation différentielle $f^{\prime \prime \prime}+f f^{\prime \prime}+2 f^{\prime 2}=0$, Ann. Sci. Math. Québec, 33, 1 (2009) 23-37.

[9] B. BRIGHI, The equation $f^{\prime \prime \prime}+f f^{\prime \prime}+\mathbf{g}\left(f^{\prime}\right)=0$ and the associated boundary value problems, Results. Math., 61, 3-4 (2012) 355-391.

[10] B. Brighi, A. Fruchard and T. Sari, On the Blasius problem, Adv. Differential Equations, 13, 5-6 (2008), 509-600.

[11] B. BRIGHI AND J.-D. HOERNEL, On similarity solutions for boundary layer flows with prescribed heat flux, Math. Methods Appl. Sci., 28, 4 (2005) 479-503.

[12] B. BRIGHI AND J.-D. HOERNEL, On the concave and convex solutions of mixed convection boundary layer approximation in a porous medium, Appl. Math. Lett., 19 (2006) 69-74.

[13] B. BRIGHI AND J.-D. HOERnEL, On a general similarity boundary layer equation, Acta Math. Univ. Comenian., 77, 1 (2008) 9-22.

[14] B. BRIGHI AND T. SARI, Blowing-up coordinates for a similarity boundary layer equation, Discrete Contin. Dyn. Syst. A, 12, 5 (2005) 929-948.

[15] B. BRIGHI AND J.-C. TS AI, Similarity solutions arising from a model in high frequency excitation of liquid metal with an antisymmetric magnetic field, IMA J. Appl. Math., 77 (2012) 157-195. 
[16] P. Cheng And W. J. Minkowycz, Free-convection about a vertical flat plate embedded in a porous medium with application to heat transfer from a dike, J. Geophys. Res., 82, 14 (1977) 2040-2044.

[17] V. M. FalkneR AND S. W. Skan, Solutions of the boundary layer equations, Phil. Mag., 7, 12 (1931) 865-896.

[18] M. GuedDA, Similarity solutions of differential equations for boundary layer approximations in porous media, J. Appl. Math. Phys. (ZAMP), 56 (2005) 749-762.

[19] M. GuedDA, Multiple solutions of mixed convection boundary-layer approximations in a porous medium, Appl. Math. Lett., 19 (2006) 63-68.

[20] P. Hartman, Ordinary Differential Equations, Wiley, New-York, 1964.

[21] H. C. KANG, J. C. YANG AND G. C. YANG, Existence and uniqueness of concave and convex solutions of mixed convection equation, Nonlinear Analysis Forum, 13, 2 (2008) 157-165.

[22] J. B. MCLEOD, The existence and uniqueness of a similarity solution arising from separation at a free stream line, Quart. J. Math. Oxford Ser. (2), 23 (1972) 63-77.

[23] J. E. PAULLET, An uncountable number of solutions for a BVP governing Marangoni convection, Math. Comput. Modelling, 52 (2010) 1708-1715.

[24] B. B. Singh AND I. M. CHANDAR KI, On the asymptotic behaviours of solutions of third order nonlinear differential equation governing the MHD flow, Differ. Equ. Appl., 3, 3 (2011) 385-397.

[25] J.-C. TSAI AND C.-A. WANG, A note on similarity solutions for boundary layer flows with prescribed heat flux, Math. Methods Appl. Sci., 30, 12 (2007) 1453-1466.

[26] G. C. YANG, An extension result of the opposing mixed convection problem arising in boundary layer theory, Appl. Math. Lett., 38 (2014) 180-185.

[27] G. C. YANG, L. ZHANG AND L. F. DANG, Existence and nonexistence of solutions on opposing mixed convection problems in boundary layer theory, European J. Mech. B/Fluids, 43 (2014) 148-153. 